\title{
THE COST OF TOLERANCE: SENSITIVITY OF STREAM BENTHIC COMMUNITIES TO UV-B AND METALS
}

\author{
Donna R. Kashian, ${ }^{1}$ Robert E. Zuellig, Katharine A. Mitchell, and William H. Clements \\ Department of Fishery and Wildlife Biology, Colorado State University, Fort Collins, Colorado 80523 USA
}

\begin{abstract}
The ability to tolerate disturbance is a defense strategy that minimizes the effects of damage to fitness and is essential for sustainability of populations, communities, and ecosystems. Despite the apparent benefits of tolerance, there may be an associated cost that results in a deficiency of a system to respond to additional disturbances. Aquatic ecosystems are often exposed to a variety of natural and anthropogenic disturbances, and the effects of these compound perturbations are not well known. In this investigation, we examine whether tolerance to one stressor, metals, results in a cost of increased sensitivity to an additional stressor, ultraviolet-B (UV-B) radiation.

Heavy metal pollution is recognized as a major environmental problem in Rocky Mountain streams. These high-elevation, typically clear streams may be at particular risk to elevated UVB levels associated with reduced levels of ozone. Microcosm experiments were conducted using natural stream benthic communities collected from a reference site and a site with a long-term history of heavy-metal pollution. Direct and interactive effects of heavy metals and UV-B radiation on structural and functional characteristics of benthic communities were evaluated among four treatments: control, UV-B, metals, and metal and UV-B. Communities from the metal-polluted site were more tolerant of metals but less tolerant to UV-B compared to reference communities. Increased mayfly drift and reduced metabolism in response to metal exposure were observed in reference communities but not in the metal-polluted communities. In contrast to these results, UV-B radiation significantly reduced community metabolism, total macroinvertebrate abundance, and abundances of mayflies, caddisflies, and dipterans from the metal-polluted site, but had no effects on benthic communities from the reference site. ANOSIM results demonstrated that community responses differed among treatments at both sites. Metals had the largest impact on community differences at both sites, while UV-B had greater impacts at the metal-polluted site. This research demonstrates the need to account for potential costs associated with tolerance and that these costs can result in behavioral, structural, and functional impacts to benthic communities.
\end{abstract}

Key words: community; compound disturbance; macroinvertebrates; metabolism; metals; streams; tolerance; ultraviolet radiation; $U V-B$.

\section{INTRODUCTION}

Ecological investigations of natural and anthropogenic disturbances have traditionally focused on single perturbations (Paine et al. 1998). For example, studies of metal-polluted streams in mining areas generally consider only the direct toxic effects of metals. These studies provide valuable information that demonstrates how metal pollution reduces genetic diversity (Beaty et al. 1998), alters the structure of benthic communities (Niyogi et al. 2002), and influences the outcome of species interactions (Clements 1999). Recent empirical and theoretical evidence suggests that community responses to multiple perturbations are not additive (Paine et al. 1998) and that communities do not always

Manuscript received 7 March 2006; revised 26 June 2006; accepted 10 July 2006. Corresponding Editor: C. Nilsson.

${ }^{1}$ Present address: Great Lakes Environmental Research Laboratory, 2205 Commonwealth Boulevard, Ann Arbor, Michigan 48105-2945 USA. E-mail: dkashian@umich.edu respond as predicted based on observations from single stressors.

Acclimating or adapting to one set of environmental stressors may increase sensitivity to novel stressors (Wilson 1988), suggesting a potential cost associated with greater tolerance. A potential mechanism to explain the cost associated with greater tolerance is described by Congdon et al. (2002). They report that repair of damages associated with contaminants increases the cost of maintenance (i.e., growth, storage, and reproduction), which in the absence of contaminants may account for as much as $80 \%$ of an organisms' energy. Therefore, an increase of energy required for maintenance resulting from contaminant exposure may negatively affect sensitive species, and the more resistant species will become more abundant. The elimination of sensitive species may result in a community that is tolerant to a specific contaminant.

Tolerance can occur at the population or community level. We define population tolerance as the ability of an organism to endure a particular level of a contaminant 
compared with other organisms of the same species experiencing similar levels of that contaminant (Burdon 1987). Community tolerance has been defined as a net increase in the resistance of a community to contaminants that results from contaminant exposure (Millward and Klerks 2002). Because of differential sensitivity to contaminants, the response of the entire community is the sum of all individual species' responses. These responses, in addition to the effects of contaminants on interactions between organisms and their environment, result in community-level changes. Thus, increased community tolerance can result from both greater tolerance at the population level and through the elimination of sensitive species.

Few studies have quantified the potential cost of tolerance and most of those studies have focused on population-level responses. Genetic changes associated with exposure to contaminants, such as reduced genetic diversity or loss of sensitive genotypes, may have longterm consequences for populations (Heagler et al. 1993). Although most of the research on the cost of tolerance has been on populations, communities from chemically stressed environments may be at greater risk from additional stressors. The community-conditioning hypothesis has been proposed to account for the persistence of toxicant effects on communities long after a contaminant has degraded (Landis et al. 1996). Because effects of disturbance are often persistent, communities are likely to proceed to an alternative stable state and may become structurally and functionally different systems. Just as genetic structure reflects the unique history of a population over evolutionary time, communities are a reflection of their unique history and etiology (Landis et al. 1996). Past events are difficult to erase and can potentially influence structural characteristics for long periods of time. We suggest that previous exposure to a stressor is a special case of the communityconditioning hypothesis, and increased tolerance to this stressor is a result of this unique historical event.

Our ability to predict responses to and recovery from multiple disturbances is greatly limited because of the focus on single disturbance events. Although the idea that chronically disturbed communities may be more susceptible to additional perturbations has theoretical support, few studies have examined multiple disturbances or attempted to quantify the potential cost of tolerance. Furthermore, the assumption that community and ecosystem responses to multiple disturbances are additive has rarely been tested.

Support for the hypothesis that chronically exposed populations and communities are more susceptible to novel stressors is provided by experiments conducted using benthic communities with a prior history of metal exposure (Clements 1999, Courtney and Clements 2000). Additionally, Kashian et al. (2004) found evidence that UV-B exposure may increase susceptibility of benthic macroinvertebrates to metal toxicity. The northern hemisphere has observed a $10-20 \%$ increase in UV-B per decade at the earth's surface associated with the anthropogenic release of chlorofluorocarbons and with ozone depletion (Kerr and McElroy 1993). Elevated UV-B levels are a concern because UV-B radiation is known to have deleterious effects on benthic communities, particularly in shallow streams (Kelly et al. 2003). An understanding of the potential effects of UV-B radiation on chronically disturbed systems is essential for predicting ecological responses.

In this research, we tested the hypothesis that benthic communities from a metal-polluted stream are more tolerant to metals but more sensitive to UV-B radiation compared to communities from a reference stream. We designed our experiments to also test the hypothesis that heavy metals and UV-B interact to structure benthic communities. We argue that the greater susceptibility of chronically disturbed communities to UV-B and other novel stressors represents a potential cost of tolerance.

\section{Methods \\ Study area}

We collected samples of benthic communities from shallow $(13-22 \mathrm{~cm})$ riffle areas in two streams in central Colorado, USA, for use in a 10-day microcosm experiment. Sites were selected based on similarities between the streams that would minimize differential responses to UV-B between sites. Samples were collected from rivers within the same watershed having similar elevation, water chemistry, dissolved organic carbon concentrations $(<2 \mathrm{mg} / \mathrm{L})$, and canopy cover. Our metal-polluted site on the Arkansas River $\left(39^{\circ} 13^{\prime} \mathrm{N}\right.$, $106^{\circ} 21^{\prime} \mathrm{W}$; elevation $2909 \mathrm{~m}$ ) near Leadville, Colorado has a history of elevated $\mathrm{Zn}, \mathrm{Cu}$, and $\mathrm{Cd}$ concentrations in water. Placer mining in the headwaters of the Arkansas River began in 1859 and therefore it is likely that metals have polluted this system for over 140 years. The reference site on West Tennessee Creek $\left(39^{\circ} 20^{\prime} \mathrm{N}\right.$, $106^{\circ} 19^{\prime} \mathrm{W}$; elevation $3090 \mathrm{~m}$ ), a tributary to the Arkansas River, was selected because it has no known history of metal contamination and because other physicochemical and habitat characteristics were similar to those in the metal-polluted stream.

\section{Microcosm experiments}

Natural macroinvertebrate communities for microcosm experiments were collected from the two sites using colonization trays $(10 \times 10 \times 6 \mathrm{~cm})$ filled with pebbles and small cobbles. Sixty colonization trays were secured on wooden racks that were anchored to each streambed during July 2003. After a 40-50 day colonization period, trays were removed from the stream using a fine-mesh net and placed in separate insulated containers (three trays per container) equipped with a portable aeration system. Trays were transferred to experimental streams located in the Stream Research Laboratory at Colorado State University (Fort Collins, Colorado, USA). Previous experiments have shown that benthic communities collected using this technique are similar to those 
collected from the natural substrate (Clements 1999, Courtney and Clements 2000). The experimental streams $(76 \times 46 \times 14 \mathrm{~cm})$ are located in a greenhouse that filters out $97 \%$ of incoming solar UV radiation $(280-400 \mathrm{~nm})$, while allowing the transmission of $\sim 50-80 \%$ of photosynthetically active radiation (PAR; 400-500 nm; Kiffney et al. 1997b). Water in the stream microcosms is obtained directly from a nearby reservoir and has similar physicochemical characteristics as unpolluted Rocky Mountain streams (Clements 1999). Current in the flow-through streams is provided by paddlewheels, and standpipes covered with fine mesh prevent the loss of drifting organisms.

Two 10-day consecutive microcosm experiments were conducted between August and September 2003 using benthic communities obtained from the reference and metal-polluted sites. For the metal-polluted community, experimental streams were randomly assigned to one of four treatments (four replicates per treatment): control, UV-B, metals, and metal and UV-B. The experimental design for the reference community was identical except that one additional replicate $(n=5)$ was used for the metal and metal and UV-B treatments. Stock solutions of metals were delivered to each treated stream from separate $20-\mathrm{L}$ containers using peristaltic pumps to achieve target concentrations of $400 \mu \mathrm{g} \mathrm{Zn} / \mathrm{L}, 20 \mu \mathrm{g}$ $\mathrm{Cu} / \mathrm{L}$, and $4 \mu \mathrm{g} \mathrm{Cd} / \mathrm{L}$. These concentrations are similar to those measured at polluted sites in the Arkansas River. UV-B radiation was generated by one SF 20 lamp (UVB-313, National Biological, Twinsbury, Ohio, USA) suspended $15 \mathrm{~cm}$ above the water surface of each treated stream and directly above the trays. UV-B exposure occurred from 06:00 to 16:00 each day to bracket solar noon.

Stream temperature, $\mathrm{pH}$, conductivity, and dissolved oxygen were measured daily in experimental streams and in the field when trays were collected. Water samples $(500 \mathrm{~mL})$ were collected on day 5 and day 10 for determination of hardness and alkalinity (APHA 1992), factors that determine metal toxicity. Cumulative UV-B exposure was quantified for the duration of the experiment using polysulphone dosimeters. Dosimeters were read using a spectrophometer and UV-B exposure was estimated using methodology established in Davis et al. (1976). To verify target metal levels in the microcosms, water samples $(14 \mathrm{~mL})$ were collected in acidwashed containers on three occasions during each experiment and acidified with nitric acid $(\mathrm{pH} \leq 2.0)$. Metal concentrations were analyzed using flame ( $\mathrm{Zn})$ and furnace $(\mathrm{Cd}, \mathrm{Cu})$ atomic absorption spectroscopy.

Macroinvertebrate drift, a behavioral response known to be sensitive to both heavy metals (Clements 1999) and UV-B (Kiffney et al. 1997b), was measured in each experimental stream by placing a small net immediately downstream from the trays on day 5 , corresponding with the UV-B exposure (06:00-16:00). Organisms caught in the drift net were removed from the stream and preserved in $80 \%$ ethanol. Net community metab- olism was measured at the conclusion of the experiment by removing two trays from the streams and randomly placing them into either a transparent or an opaque individually sealed 3.0-L airtight incubation chamber. Each chamber, filled with source water and incubated in a water bath to maintain temperature, contained a pump that circulated water at a velocity comparable to that of the streams. Net community metabolism (gross productivity - total respiration) was measured as the change in dissolved oxygen concentration in the overlying water of these chambers after a one-hour incubation. Because entire communities were used, we were unable to estimate relative contributions of microbial, periphyton, or macroinvertebrate respiration. After measuring metabolism, the three trays from each stream were combined and the contents rinsed through a $350-\mu \mathrm{m}$ mesh sieve. Organisms were preserved in $80 \%$ ethanol, sorted, and all individuals (except Chironomidae) were identified to genus or species. Chironomidae were further separated into sub-families (Tanypodinae, Orthocladiinae, and Chironominae) and the Chironominae were identified to tribe (Chironomini and Tanytarsini).

We used two-way ANOVA to test for main effects (UV-B and metals) and the UV-B $\times$ metal interaction on the total number of taxa, total number of individuals, abundances of major macroinvertebrate orders (Ephemeroptera, Plecoptera, Trichoptera, and Diptera), abundance of species common to both sites, mayfly drift, and community metabolism for each experiment. The two experiments were analyzed separately because they were not conducted simultaneously and because of known differences in community composition between reference and metal-polluted sites. Where necessary, data were log transformed to meet assumptions of parametric statistics, if inspection of residuals plots indicated lack of normality or heterogeneity of variances among treatments.

A nonparametric multivariate technique based on Bray-Curtis similarity and square-root transformed abundance data was used to investigate community relationships among treatment groups (Clarke and Warwick 2001). Square-root transformation allows for common and intermediately abundant taxa to contribute to community similarity among samples while downweighting rare taxa. Nonmetric multidimensional scaling (MDS) ordinations were constructed for both sites to graphically illustrate relationships among treatment groups. The main advantages of MDS over other ordination techniques is that MDS does not make any assumptions about the form of the data or the interrelationships of the samples, and it has greater ability to represent complex relationships in low dimensional space. A goodness-of-fit of the MDS ordinations was assessed by the magnitude of the associated stress value. A low stress value $(<0.2)$ corresponds to a good ordination with no real prospect of a misleading interpretation. One-way analysis of similarity (ANOSIM) was used to determine significant 
TABLE 1. Physiochemical characteristics (mean $\pm \mathrm{SD}$ ) at reference (West Tennessee Creek) and metal-polluted (Arkansas River) field sites (Colorado, USA) and in stream microcosms.

\begin{tabular}{|c|c|c|c|c|}
\hline \multirow[b]{2}{*}{ Characteristics } & \multicolumn{2}{|c|}{ Field sites } & \multicolumn{2}{|c|}{ Experimental streams } \\
\hline & Reference & Metal polluted & Reference & Metal polluted \\
\hline Alkalinity (mg/L) & 15 & 63 & $41.3 \pm 1.4$ & $44.0 \pm 1.4$ \\
\hline Conductivity $(\mu \mathrm{S} / \mathrm{cm})$ & 32 & 288 & $80.3 \pm 2.5$ & $78.8 \pm 2.1$ \\
\hline Dissolved oxygen $(\mathrm{mg} / \mathrm{L})$ & 6.65 & 8.98 & $6.92 \pm 0.1$ & $7.17 \pm 0.2$ \\
\hline Hardness, $\mathrm{CaCO}_{3}(\mathrm{mg} / \mathrm{L})$ & 14 & 136 & $41.1 \pm 3.5$ & $40.3 \pm 1.3$ \\
\hline $\mathrm{pH}$ & 7.32 & 7.9 & $7.13 \pm 0.8$ & $7.57 \pm 0.6$ \\
\hline Temperature $\left({ }^{\circ} \mathrm{C}\right)$ & 15.7 & 15.3 & $16.1 \pm 0.0$ & $16.1 \pm 0.1$ \\
\hline $\mathrm{Cu}(\mu \mathrm{g} / \mathrm{L})$ & 0.6 & 2.5 & $16.9 \pm 0.2$ & $21.8 \pm 0.9$ \\
\hline $\mathrm{Cd}(\mu \mathrm{g} / \mathrm{L})$ & 0.2 & 0.7 & $3.2 \pm 0.1$ & $4.4 \pm 0.9$ \\
\hline $\mathrm{Zn}(\mu \mathrm{g} / \mathrm{L})$ & 5.0 & 461 & $427.0 \pm 7.1$ & $447.0 \pm 14.1$ \\
\hline $\mathrm{UV}-\mathrm{B}\left(\mathrm{J} / \mathrm{cm}^{2}\right)$ & $4.0 \dagger$ & $3.1 \dagger$ & $5.6 \pm 1.8$ & $6.2 \pm 2.4$ \\
\hline
\end{tabular}

Notes: Experimental stream values were averaged across the control streams for all characteristics except for metals. Mean concentrations of $\mathrm{Cu}, \mathrm{Cd}$, and $\mathrm{Zn}$ in microcosms are presented from the metals and metals + UV-B treatments only. Metal concentrations in control and UV-B streams were below detection limit. UV-B values in non-UV-B treated streams were below $0.5 \mathrm{~J} / \mathrm{cm}^{2}$.

$\dagger$ Dosimeter readings in the field were taken over an 11-day period, and were adjusted to correspond with the 10-day greenhouse experiment.

differences among treatment groups. ANOSIM is a nonparametric permutation procedure applied to the rank similarity matrix underlying the MDS ordination that compares the degree of separation among treatment groups using the test statistic, $R$. When $R$ approaches 0 it indicates that there is no distinguishable separation among treatment groups, whereas when $R$ approaches 1 it is an indication of complete separation. The test statistic is first calculated as a global test to determine if significant differences are present somewhere among treatment groups. The significance level of the $R$ statistic is calculated by comparing the observed $R$ value to its permutation distribution. If the global test indicates significant differences at $\alpha=0.05$, then pairwise comparisons of each treatment group were examined. All multivariate analyses were conducted using the PRIMER-E software package (PRIMER-E, version 6.1, Plymouth Marine Laboratory, Plymouth, UK).

\section{Results}

\section{Water quality and $U V-B$ exposures}

Water temperature and $\mathrm{pH}$ were similar in experimental streams and at the two field sites (Table 1). Conductivity, alkalinity, and water hardness were, however, higher at the metal-polluted site (Arkansas River) compared to the reference site (West Tennessee Creek) and the experimental streams. As predicted, metal concentrations were elevated at the metal-polluted site compared to the reference site. Mean $\mathrm{Cd}, \mathrm{Cu}$, and $\mathrm{Zn}$ concentrations in treated microcosm streams were comparable between experiments. Although metal concentrations measured in the Arkansas River were less than those in metal-treated streams, concentrations at this site vary seasonally and are often much higher during spring runoff (Clements and Kiffney 1994). Metal concentrations in the control and UV-B treatments were always below detection. UV-B levels were similar between the two microcosm experiments and were elevated by $\sim 5.4 \mathrm{~J} / \mathrm{cm}^{2}$ in the UV-B treatments compared to the controls.

\section{Initial community composition}

Through an examination of control treatments in each experiment, we determined that initial benthic community composition at the two sites was generally similar. With the exception of midges, the proportion of individuals within the major taxonomic groups was comparable. Midges (primarily Orthocladiinae) comprised $87 \%$ of the community at the reference site compared with only $27 \%$ at the impacted site. Excluding this group, we identified community characteristics that were likely influenced by metal exposure history. Caddisflies, organisms considered relatively tolerant of heavy metals (Cain et al. 1992), made up a larger proportion of the non-dipteran macroinvertebrate community from the metal-polluted site (73\%) compared with the reference site $(52 \% ; P=0.008)$. Likewise, mayflies, organisms considered sensitive to heavy metals (Clements et al. 2000), were 13\% more abundant at the reference site compared with the metal polluted site $(P=$ $0.04)$.

\section{Benthic community response}

Regardless of community history, the high levels of metals in the microcosm experiments adversely impacted benthic communities. The community from the reference site, however, experienced a greater impact of the metals. For example, drift of mayflies increased significantly in metal-treated streams originating from the reference site $\left(F_{3,17}=29.734, P<0.0001\right)$ but was similar between treatments in the community from the metal-polluted site $\left(F_{3,15}=0.158, P=0.70\right.$, Fig. 1$)$. Likewise, community metabolism was significantly reduced in metal-treated streams where the communities came from the reference site (Fig. 2). 


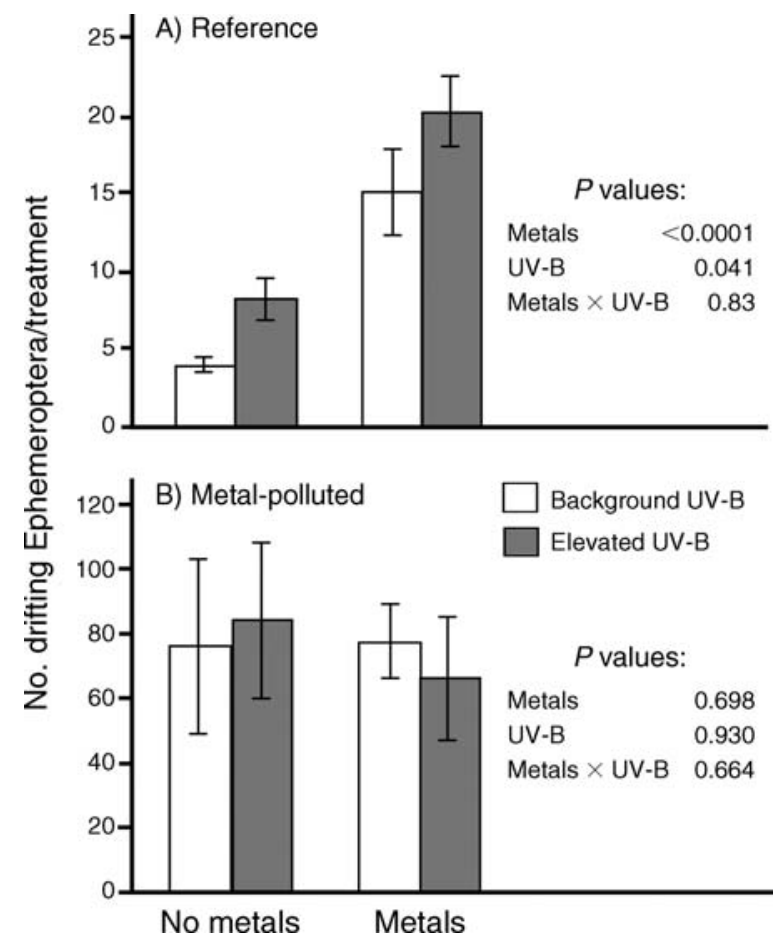

FIG. 1. Effects of metals and UV-B radiation on drift of mayflies (mean $\pm \mathrm{SE}$ ) from $(\mathrm{A})$ reference and (B) metalpolluted communities. Results of two-way ANOVA showing metals, UV-B, and metals $\times$ UV-B interaction are shown.

Metals significantly reduced abundance of caddisflies only for the community from the reference site $(P=$ 0.002; Fig. 3, Table 2). Although total macroinvertebrate abundance, taxa richness, abundance of mayflies, and abundance of dipterans were reduced for both communities, the magnitude of effect was consistently greater for the community from the reference site. Compared to controls, total macroinvertebrate abundance in metal-treated streams was reduced by $41 \%$ for the community from the metal-polluted site compared to the $88 \%$ reduction for the community from the reference site. Similarly, abundance of caddisflies in the metal treatment was reduced by only $9 \%$ for the community from the metal-polluted site and by $34 \%$ for the community from the reference site. Finally, species richness was only $10 \%$ lower in metal treatments for the community from the metal-polluted site compared to $26 \%$ for the community from the reference site. Differences in sensitivity to metals between sites were also observed for the dominant taxa that were common to both sites (Table 2). The dominant mayflies common to both sites were significantly reduced at both sites. However, several species of caddisflies, Arctopsyche grandis, Lepidostoma ormeum, and Hydropsyche oslari, were substantially (significant or nearly significant, $P \leq$ 0.10 ) reduced by metals only from the community from the reference site (Table 2).
In contrast to the effects of metals, significant effects of UV-B on benthic community composition and metabolism were primarily limited to the community from the metal-polluted site. Total macroinvertebrate abundance $(P=0.0002)$ and abundance of mayflies $(P=$ $0.0002)$, dipterans $(P=0.044)$, and caddisflies $(P=$ 0.0008 ) were significantly lower in the UV-B treatments originating from the metal-polluted site. Five of the nine common taxa between sites were significantly reduced from the community from the metal-polluted site (Table 2). Community metabolism decreased significantly $(P=$ 0.033 ) in UV-B treatments for the community from the metal-polluted site, but no effects were observed for the community from the reference site (Fig. 2). Mayfly drift increased significantly only in UV-B treatments at the community from the reference site (Fig. 1).

UV-B appeared to have a larger incremental effect on community metabolism on the community from the metal-polluted site (Fig. 2.). With the exception of Baetis bicaudatus from the reference community, there was little indication of potential synergistic effects of metals and UV-B exposure for any structural measures (Table 2).

MDS ordinations showed a greater degree of separation between communities in treatments with and without metals from the reference-site community,

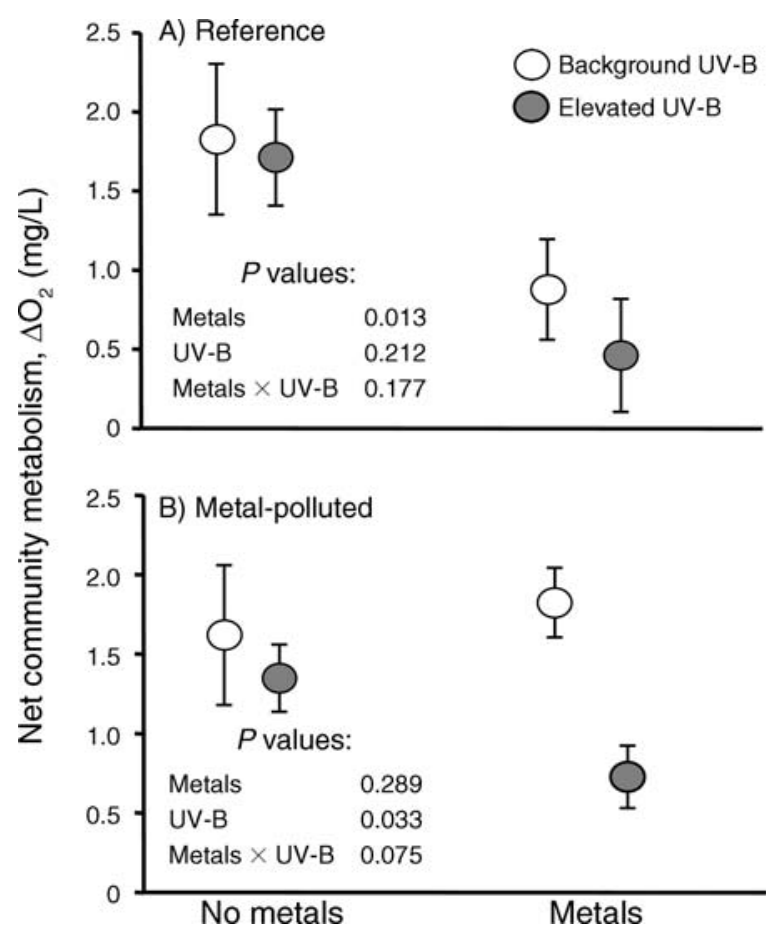

FIG. 2. Effects of metals and UV-B radiation on community metabolism $( \pm \mathrm{SE})$ of $(\mathrm{A})$ reference and $(\mathrm{B})$ metal-polluted communities after exposure to heavy metals and UV-B radiation. Metabolism was calculated as the change in dissolved- $\mathrm{O}_{2}$ concentration in a $3-\mathrm{L}$ metabolism chamber over one hour. Results of two-way ANOVA showing metals, UV-B, and metals $\times$ UV-B interaction are shown. 

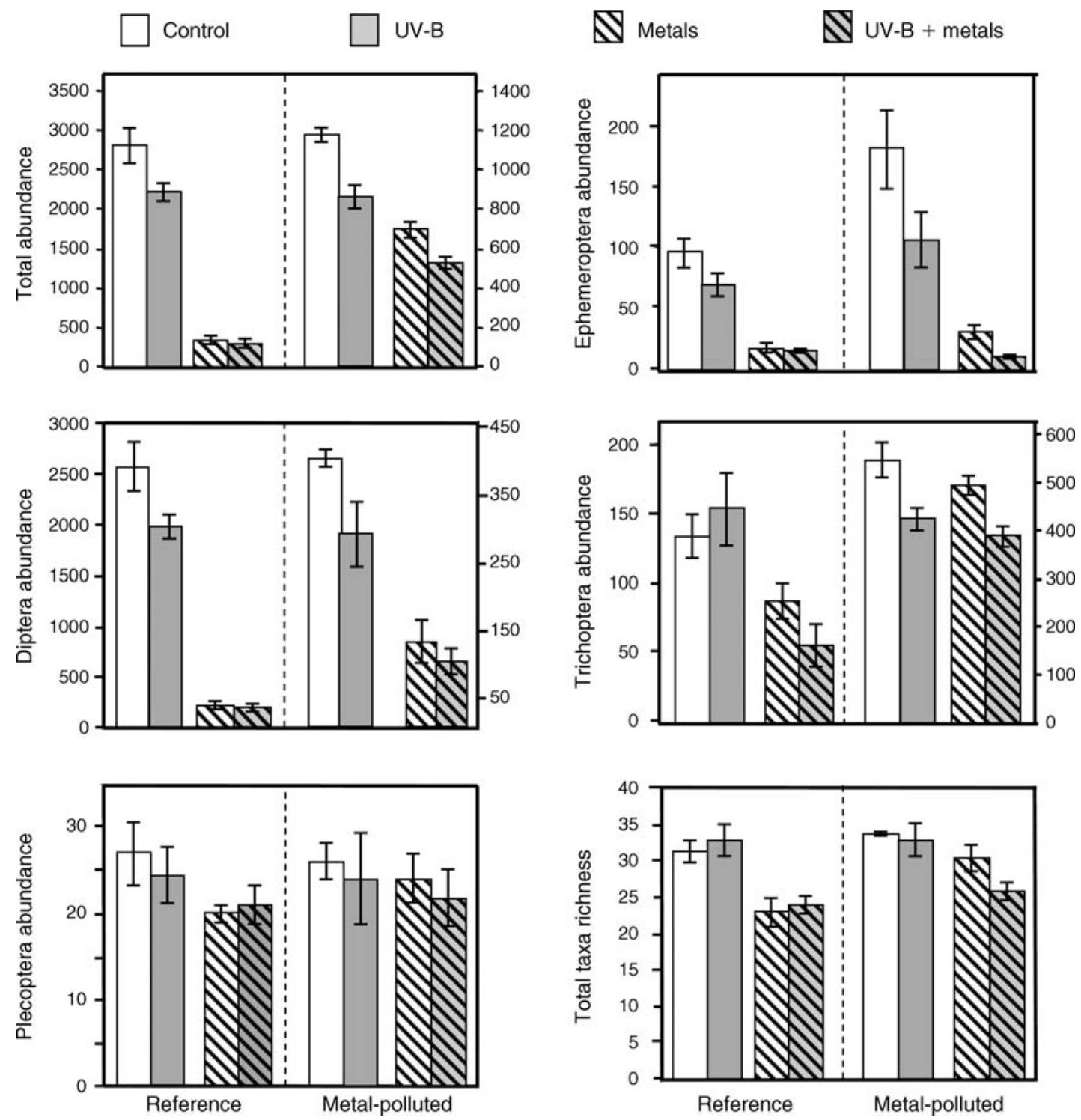

FIG. 3. Effects of metals and UV-B radiation on total macroinvertebrate abundance, number of taxa, and abundance of major macroinvertebrate groups from reference and metal-polluted communities; values are means \pm SE. Total abundance was quantified from three trays measuring $10 \times 10 \times 6 \mathrm{~cm}$. See Table 2 for results of two-way ANOVA showing metals, UV-B, and metals $\times$ UV-B interaction.

compared to communities collected from the metalpolluted site (Fig. 4). Both ordinations have low twodimensional stress values, indicating a good representation of the data. ANOSIM indicated that treatment differences were present at both sites (metal-polluted site, global $R=0.636, P=0.001$; reference site global $R=$ $0.654, P=0.001)$. Pairwise comparisons further showed that communities from treatments with metals were separable from treatments without metals at both sites, but metal treatments had greater effects at the reference site (Table 3). Although communities in the control and UV-B treatments from the reference site were distinguishable by the ANOSIM procedure $(R=0.365, P=$
0.029), separation between these groups was relatively weak.

\section{Discussion}

Humans influence the ecology of every ecosystem by changing the survival and reproduction of organisms. These changes influence the way organisms respond to disturbance. We demonstrate that long-term exposure to metals can result in a metal-tolerant community, which in turn is more sensitive to UV-B than similar communities without a history of metal contamination. However, it is important to note that differences between the two microcosm experiments cannot be exclusively attributed to treatment effect because com- 
TABLE 2. Results of two-way ANOVA showing the effects of heavy metals and UV-B radiation on total macroinvertebrate abundance, number of taxa, abundance of major macroinvertebrate groups, and abundance of common taxa from reference and metal-polluted communities.

\begin{tabular}{|c|c|c|c|c|}
\hline \multirow{2}{*}{$\begin{array}{c}\text { Metrics and } \\
\text { dominant taxa }\end{array}$} & \multicolumn{2}{|c|}{$\begin{array}{l}\text { Reference } \\
\text { community }\end{array}$} & \multicolumn{2}{|c|}{$\begin{array}{l}\text { Metal-polluted } \\
\text { community }\end{array}$} \\
\hline & $F_{3,17}$ & $P$ & $F_{3,15}$ & $P$ \\
\hline \multicolumn{5}{|l|}{ Total abundance } \\
\hline metals & 178.77 & $<0.0001$ & 75.87 & $<0.0001$ \\
\hline UV-B & 1.40 & 0.257 & 27.12 & 0.0002 \\
\hline metals $\times$ UV-B & 0.07 & 0.796 & 0.20 & 0.662 \\
\hline \multicolumn{5}{|l|}{ Taxa richness } \\
\hline metals & 19.96 & 0.0005 & 10.74 & 0.0066 \\
\hline UV-B & 0.49 & 0.496 & 3.20 & 0.0988 \\
\hline metals $\times$ UV-B & 0.00 & 0.950 & 1.50 & 0.244 \\
\hline \multicolumn{5}{|c|}{ Ephemeroptera abundance } \\
\hline metals & 101.88 & $<0.0001$ & 29.75 & 0.001 \\
\hline UV-B & 1.45 & 0.249 & 29.01 & 0.0002 \\
\hline metals $\times$ UV-B & 0.55 & 0.469 & 0.13 & 0.720 \\
\hline \multicolumn{5}{|l|}{ Diptera abundance } \\
\hline metals & 180.17 & $<0.0001$ & 53.018 & $<0.0001$ \\
\hline UV-B & 0.60 & 0.449 & 5.064 & 0.044 \\
\hline metals $\times$ UV-B & 0.29 & 0.596 & 1.801 & 0.204 \\
\hline \multicolumn{5}{|l|}{ Trichoptera abundance } \\
\hline metals & 15.55 & 0.0015 & 2.71 & 0.126 \\
\hline UV-B & 1.56 & 0.232 & 19.77 & 0.0008 \\
\hline metals $\times$ UV-B & 2.69 & 0.123 & 0.00 & 0.948 \\
\hline \multicolumn{5}{|l|}{ Plecoptera abundance } \\
\hline metals & 3.26 & 0.0926 & 0.22 & 0.645 \\
\hline UV-B & 0.16 & 0.697 & 0.53 & 0.479 \\
\hline metals $\times$ UV-B & 0.25 & 0.623 & 0.00 & 0.999 \\
\hline \multicolumn{5}{|l|}{ Baetis bicaudatus } \\
\hline metals & 43.15 & $<0.0001$ & 7.67 & 0.0170 \\
\hline UV-B & 2.40 & 0.144 & 16.94 & 0.0014 \\
\hline metals $\times$ UV-B & 9.96 & 0.0070 & 0.01 & 0.942 \\
\hline \multicolumn{5}{|l|}{ Baetis tricaudatus } \\
\hline metals & 35.52 & $<0.0001$ & 21.13 & 0.0006 \\
\hline UV-B & 3.56 & 0.0800 & 28.60 & 0.0002 \\
\hline metals $\times$ UV-B & 1.17 & 0.298 & 0.42 & 0.530 \\
\hline \multicolumn{5}{|l|}{ Diphetor hageni } \\
\hline metals & 269.48 & $<0.0001$ & 166.91 & $<0.0001$ \\
\hline UV-B & 1.00 & 0.334 & 1.93 & 0.190 \\
\hline metals $\times$ UV-B & 0.03 & 0.858 & 0.03 & 0.860 \\
\hline \multicolumn{5}{|l|}{ Ephemerella infrequens } \\
\hline metals & 9.93 & 0.0071 & 16.27 & 0.0017 \\
\hline UV-B & 2.40 & 0.144 & 4.69 & 0.0512 \\
\hline metals $\times$ UV-B & 0.60 & 0.453 & 1.88 & 0.195 \\
\hline \multicolumn{5}{|l|}{ Arctopsyche grandis } \\
\hline metals & 3.17 & 0.0969 & 0.97 & 0.344 \\
\hline UV-B & 0.01 & 0.919 & 0.67 & 0.429 \\
\hline metals $\times$ UV-B & 0.31 & 0.586 & 0.14 & 0.719 \\
\hline \multicolumn{5}{|l|}{ Hydropsyche oslari } \\
\hline metals & 14.34 & 0.0020 & 0.54 & 0.477 \\
\hline UV-B & 3.02 & 0.104 & 7.36 & 0.0189 \\
\hline metals $\times$ UV-B & 0.62 & 0.445 & 0.01 & 0.920 \\
\hline \multicolumn{5}{|c|}{ Brachycentrus americanus } \\
\hline metals & 2.02 & 0.178 & 0.97 & 0.343 \\
\hline UV-B & 0.11 & 0.748 & 14.04 & 0.0028 \\
\hline metals $\times$ UV-B & 0.03 & 0.859 & 0.03 & 0.857 \\
\hline
\end{tabular}

TABLE 2. Continued.

\begin{tabular}{llllll}
\hline \hline & \multicolumn{2}{c}{$\begin{array}{c}\text { Reference } \\
\text { community }\end{array}$} & & \multicolumn{2}{c}{$\begin{array}{c}\text { Metal-polluted } \\
\text { community }\end{array}$} \\
\cline { 2 - 3 } $\begin{array}{c}\text { Metrics and } \\
\text { dominant taxa }\end{array}$ & $F_{3,17}$ & $P$ & & $F_{3,15}$ & $P$ \\
\hline $\begin{array}{l}\text { Lepidostoma ormeum } \\
\text { metals }\end{array}$ & & & & & \\
UV-B & 4.16 & 0.0608 & & 0.24 & 0.632 \\
metals $\times$ UV-B & 2.74 & 0.120 & & 0.48 & 0.502 \\
Simulium spp. & 4.28 & 0.0574 & & 1.44 & 0.253 \\
metals & & & & \\
$\quad$ UV-B & 1.44 & 0.250 & & 2.20 & 0.164 \\
metals $\times$ UV-B & 0.01 & 0.906 & & 6.65 & 0.0242 \\
\hline
\end{tabular}

munities were obtained from two different streams. Despite our attempts to minimize potential confounding variables by careful site selection, factors other than a history of metal exposure may be partially responsible for the differential responses to metals and UV-B between communities.

Long-term exposure to heavy metals in the Arkansas River has significantly altered composition of benthic macroinvertebrate communities (Clements 2004). Although the Arkansas River system is open to immigration from non-polluted sites such as the West Tennessee Creek, there are differences in the occurrence of metaltolerant and metal-sensitive species between sites. Community restructuring, characterized by higher abundances of metal-tolerant species and lower abundance of metal-sensitive species, has been observed in the Arkansas River (Clements 2004). Increased tolerance of benthic macroinvertebrates to heavy metals has also been reported for metal-polluted habitats (Clements 1999, Groenendijk et al. 2002). In our study, effects of metals on total macroinvertebrate abundance, taxa richness, and abundance of caddisflies, dipterans, and mayfly drift were greater for the community from the reference than the community from the metal-polluted site. Because most studies of metal tolerance have focused on population-level responses, our understanding of the consequences of community restructuring relative to ecosystem function and resistance to other stressors is limited.

The pollution-induced community-tolerance (PICT) concept was initially proposed for marine periphyton communities and represents one of the first attempts to quantify tolerance at the community level (Blanck and Wangberg 1988). The PICT hypothesis is based on the observations that sensitivity to contaminants varies among species and that contaminants restructure communities, with tolerant species replacing sensitive species (Gustavson and Wangberg 1995). The PICT approach has been employed to demonstrate that community restructuring was a direct result of contaminant exposure, but few studies have investigated the effects of community restructuring on susceptibility to other stressors. 


\section{Treatments}
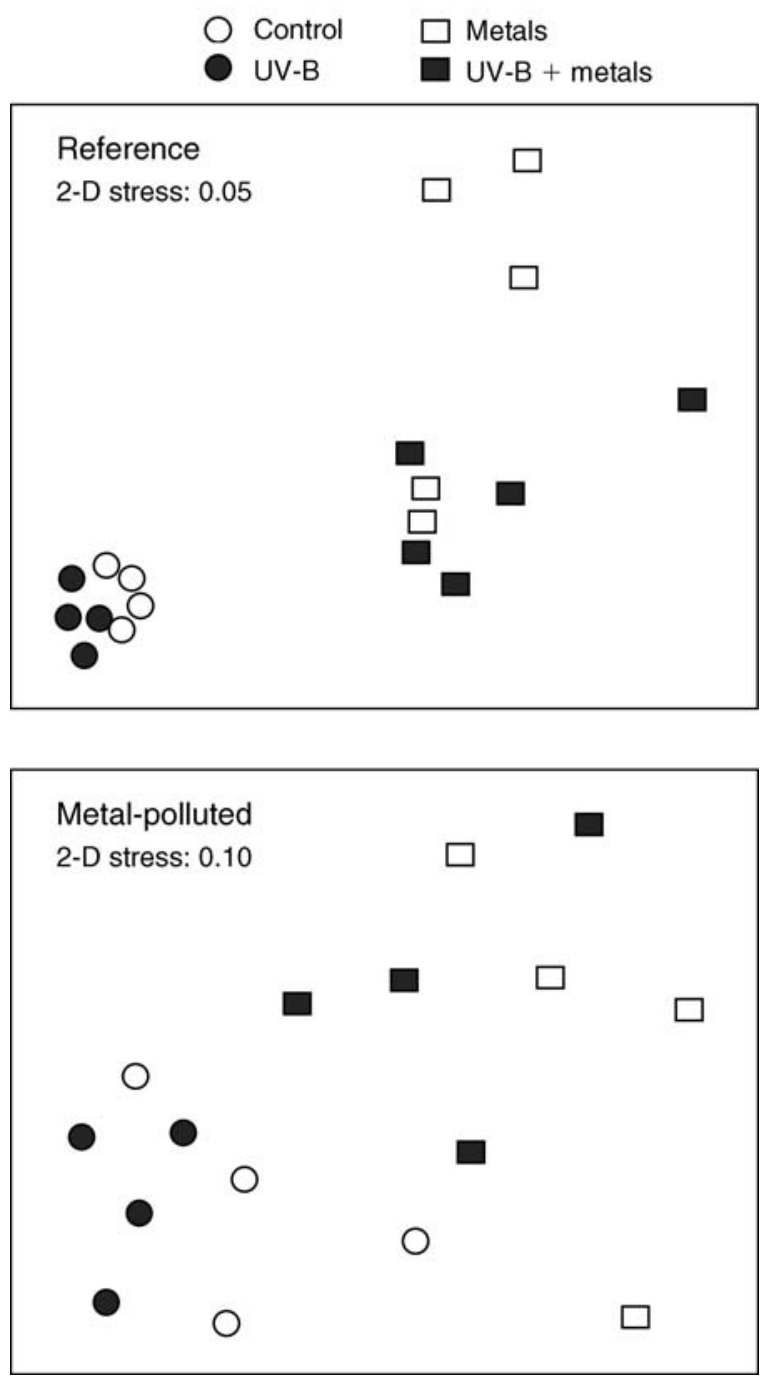

FIG. 4. Nonmetric multidimensional-scaling (MDS) ordinations of Bray-Curtis similarities of square-root transformed abundance data graphically illustrating the relationships among communities in a metal-polluted site and in a reference site exposed to four treatments in a stream microcosm experiment. The statistical term 2-D stress indicates how well the ordination is described in two dimensions.

The occurrence of additional stressors in a system is likely to have impacts at the individual, population, community, and ecosystem levels. Weis (2002) speculated that increased tolerance to metals may reduce genetic diversity in a population and that the evolution of resistance in a population could be associated with reduced fitness, causing problems for future generations. If pollution eliminates metal-sensitive genotypes in a population and results in a loss of genetic variation (Beaty et al. 1998, Van Straalen and Timmermans 2002), the ability of these populations to respond to future stressors may be reduced. Similarly, elimination of sensitive species from a community will potentially alter ecosystem processes (Cardinale and Palmer 2002) and may increase susceptibility of the restructured community to other natural and anthropogenic perturbations (Paine et al. 1998). This hypothesis is consistent with predictions of Scheffer et al. (2001) that long-term disturbances may increase ecosystem fragility, thus increasing the susceptibility to other stressors.

The observed differences in behavioral and structural responses to metals between the two communities in this study are likely attributed to one of three processes. Two of these processes, genetic adaptation and physiological acclimation, act at the population level, while species replacement is a community-level response. At the population level, genetic adaptation of aquatic invertebrates to heavy metal pollution is well established, and the most compelling evidence has been obtained by quantifying tolerance of offspring derived from metaltolerant adults (Groenendijk et al. 2002). Although obtaining $F_{1}$ generations of aquatic macroinvertebrates is possible for some groups (e.g., oligochaetes, amphipods, some chironomids), experimentally demonstrating adaptation is challenging for most aquatic insects because of difficulties maintaining multiple generations in the laboratory. In this study, we observed the same concentration of metals adversely impacting specific taxa at the reference site while having no impact on the same taxa from the metal-polluted site indicating selection pressures on sensitive genotypes. Physiological mechanisms responsible for acclimation of aquatic insects to metals include metal sequestration, production of metalbinding proteins, and metal compartmentalization (Hare 1992). We have previously suggested that metal tolerance of mayflies from the Arkansas River was likely a result of both intraspecific and interspecific mechanisms (Clements 1999, Courtney and Clements 2000). In addition to shifts in abundance of dominant species, we also have observed reduced genetic diversity (Beaty et al. 1998) and elevated levels of metal-binding proteins (Harrahy 2000) in the mayfly Baetis tricaudatus collected from metalpolluted stations in this system. In this study, it appears that differences in responses to metals between reference and metal-polluted communities were likely a result of

TABLE 3. Summary results of one-way analysis of similarities (ANOSIM) for a metal-polluted and a reference site in the Central Rocky Mountains of Colorado.

\begin{tabular}{lcc}
\hline \hline \multicolumn{1}{c}{ Groups } & $\begin{array}{c}\text { Reference site } \\
R(P \text { value })\end{array}$ & $\begin{array}{c}\text { Metal-polluted site } \\
R(P \text { value })\end{array}$ \\
\hline Control vs. UV-B & $0.240(0.143)$ & $0.365(0.029)$ \\
Control vs. metals & $0.994(0.008)$ & $0.813(0.029)$ \\
Control vs. metals and & $1.000(0.008)$ & $1.000(0.029)$ \\
$\quad$ UV-B & $0.913(0.008)$ & $0.583(0.029)$ \\
$\begin{array}{l}\text { UV-B vs. metals } \\
\text { UV-B vs. metals and } \\
\quad \text { UV-B }\end{array}$ & $0.969(0.008)$ & $0.865(0.029)$ \\
$\begin{array}{l}\text { Metals vs. metals and } \\
\quad \text { UV-B }\end{array}$ & $0.080(0.238)$ & $0.260(0.086)$ \\
\hline
\end{tabular}

Note: The global $R$ statistic was $0.636(P=0.001)$ at the metal polluted site and $0.654(P=0.001)$ at the reference site. 
both population-level responses (e.g., acclimation or adaptation) and the replacement of metal-sensitive species by metal-tolerant species at the Arkansas River. This was evident through initially higher abundances of metal-tolerant caddisflies and lower abundances of metal-sensitive mayflies from the impacted site.

We have provided evidence that benthic populations and communities at the metal-polluted site were more tolerant to metals compared to those from the reference site. Next we will consider the biological importance of UV-B and evaluate how the two communities respond to this additional stressor. Although ultraviolet radiation is a natural component of the solar spectrum, UV-B is known to have deleterious impacts on aquatic populations (Damkaer et al. 1981), communities (Vinebrooke and Leavitt 1999), and ecosystems (Bothwell et al. 1994). Dramatic reductions in primary production and alterations in benthic community composition and trophic structure have been reported following exposure to UV-B (Bothwell et al. 1994, Kiffney et al. 1997a). Because of the shallow depth and naturally low levels of light-attenuating dissolved organic materials in Rocky Mountain streams (Baron et al. 1992), benthic communities are exposed to intense levels of UV-B radiation during summer (Kiffney 1997a). In addition, because solar intensity increases significantly with elevation, communities in subalpine and montane streams are at particular risk from UV-B exposure. Finally, enzyme repair processes of invertebrates are temperature dependent, and therefore organisms inhabiting cold mountain streams may be less effective at repairing UV-B damage (Macfadyen et al. 2004).

Exposure to elevated UV-B radiation in stream microcosms had relatively little effect on the reference community. Although mayfly drift increased in UV-B treatments, none of the community metrics that we examined were reduced by UV-B exposure in the reference microcosm streams. The significant effect of UV-B on benthic macroinvertebrates observed in stream microcosms was consistent with results of previous field studies (Kiffney et al. 1997a, Kelly et al. 2003). The most dramatic effects of UV-B at the metal-polluted site were observed for mayflies, which were reduced by $41 \%$ in UV-B streams, compared to controls. Baetids dominated the mayfly assemblages in our streams. These organisms often graze the surface of rocks and were likely exposed to the highest levels of UV-B. Reduced abundance of dipterans in our experiment was largely attributed to effects on orthoclad midges, a group previously shown to be highly sensitive to UV-B (Bothwell et al. 1994). Species sensitivities of caddisflies to UV-B varied between sites. Although some researchers have speculated that differences in sensitivity to UV$B$ radiation among species are related to the degree of protection provided by shells, cases, tubes, and retreats (Hill et al. 1997, Kiffney et al. 1997a), we observed significant effects on both cased and noncased caddis- flies. Therefore, the ability to retreat in cases or tubes did not appear to mitigate the effects of UV-B in our study.

The significant effect of UV-B on community metabolism observed in our experiments was also consistent with studies of primary productivity and metabolism in other aquatic ecosystems (Day and Neale 2002). Most research investigating effects of UV-B on community metabolism has been conducted either in marine ecosystems (Smith et al. 1992) or lakes (Williamson 1995, Watkins et al. 2001), while relatively few studies have quantified effects of UV-B on stream benthic communities. Kiffney et al. (1997a) reported that chlorophyll $a$ was reduced by $\sim 50 \%$ in a Colorado stream exposed to natural levels of UV-B compared to no UV-B treatments. Bothwell et al. (1994) attributed increased algal biomass in streams exposed to UV-B to the elimination of chironomid grazers. This finding illustrates that complex interactions between periphyton and grazers will likely complicate our ability to predict effects of UV-B on primary production in streams. We suggest that Arkansas River communities have been restructured by longterm heavy-metal pollution and the resulting assemblages are more susceptible to UV-B radiation. This finding is consistent with our previous studies that showed that metal-polluted communities in the Arkansas River were more susceptible to acidification (Courtney and Clements 2000) and predation by stoneflies (Clements 1999), compared to communities from reference sites.

Finally, we would like to address the hypothesis by Paine et al. (1998) that community responses to multiple perturbations are not additive and that communities do not always respond as predicted based on observations from single stressors. We addressed the effects of multiple stressors through a comparison of the individual and combined effects of metals and UV-B on communities. Community responses to these multiple disturbances were inconsistent and unpredictable. Community metabolism showed a nearly significant metals $\times U V-B$ interaction at the metal-polluted site, supporting our predictions. However, only two species, the mayfly Baetis bicaudatus and the caddisfly Lepidostoma ormeum, showed a significant metals $\times$ UV-B interaction, and these responses, contrary to our predictions, were limited to the reference community. Other researchers have reported synergistic interactions between UV-B and other abiotic stressors, including nutrient enrichment (Xenopoulous et al. 2002), increased temperature (Przeslawski et al. 2005), and heavy metals (West et al. 2003). This research suggests that some of the unpredictable responses associated with multiple disturbances that Paine et al. (1998) identify may, in part, be from differential tolerances that affect the capacity of an organism to respond to additional disturbances, hence a cost of tolerance.

\section{Conclusions}

Our experiments demonstrated that benthic communities subjected to long-term metal pollution in the Arkansas River were generally more tolerant to metals 
but more sensitive to UV-B radiation than communities from a nearby reference stream. Therefore, it appears that there is a trade-off between metal tolerance and UV-B sensitivity. The mechanism of this phenomenon remains unclear at this time, but indicates a cost associated with metal tolerance. Greater tolerance to metals and greater susceptibility to UV-B in the Arkansas River community was likely a result of population-level responses (acclimation and adaptation) and shifts in community composition. Our results demonstrate the importance of accounting for site history, community composition, and stressor interactions when attempting to predict how communities will respond to anthropogenic perturbations. We suggest that site history and the associated cost of tolerance should be considered when conducting ecological risk assessments for individual stressors. These complex interactions between metals, UV-B, and site history could not have been predicted by examining either stressor alone. We propose that failure to account for stressor interactions or to consider the influence of site history may result in serious underestimates of the ecological impacts of multiple stressors.

Our findings have important implications for understanding how community composition can influence responses to anthropogenic disturbance. One of the more contentious debates in modern ecology concerns the theoretical relationship between species diversity and community resilience. Several of the models developed to describe this relationship hypothesize that because of greater functional redundancy, species-rich communities will be less susceptible to anthropogenic perturbations than species-poor communities (Peterson et al. 1998). Despite differences in community composition between the reference stream and the Arkansas River, total species richness was similar (Fig. 3). Thus, differences in the susceptibility of reference and Arkansas River communities to metals and UV-B were not determined by differences in species richness. The ability of organisms to tolerate a disturbance has evolutionary consequences if selection pressures favor tolerant individuals and thus impact genetic diversity. Understanding the mechanisms maintaining diversity in natural populations is important for conservation biology and crucial to our understanding of the longterm impacts of contaminants in the environment. Our findings suggest that differences in community composition are likely to be more important than species richness in determining responses to anthropogenic perturbations and the consequences of these perturbations for ecosystem processes.

\section{ACKNOWLedGMents}

This research was funded by the U.S. Environmental Protection Agency STAR Program, grant number R829640. We thank Crystal Halverson, Dan Kashian, and Heather Lyons for help in the field. Thanks to the U.S. Forest Service (Arapahoe National Forest) and Edith Seppi for allowing access to field sites on the Arkansas River and Marj Brooks-
Lovvorn for providing expertise on calibrations for the dosimeters used in this study. Comments on the manuscript by Jill Baron, Barry Noon, Kurt Fausch, and two anonymous reviewers are greatly appreciated.

\section{Literature Cited}

APHA (American Public Health Association). 1992. Standard methods for the examination of water and wastewater. 18th edition. American Public Health Association. Washington, D.C., USA.

Baron, J., D. McKnight, and A. S. Denning. 1992. Sources of dissolved and suspended organic material in Loch Vale watershed, Rocky Mountain National Park, Colorado, USA. Biogeochemistry 15:89-110.

Beaty, B. J., W. C. Black, J. O. Carlson, W. H. Clements, N. DuTeau, E. Harrahy, J. Nuckols, K. E. Olson, and A. Rayms-Keller. 1998. Molecular and genetic ecotoxicological approaches to aquatic environmental bioreporting. Environmental Health Perspectives 106:1395-1407.

Blanck, H., and S. Wangberg. 1988. Induced community tolerance in marine periphyton established under arsenate stress. Canadian Journal of Fisheries and Aquatic Sciences 45:1816-1819.

Bothwell, M. L., D. M. J. Sherbot, and C. M. Pollock. 1994. Ecosystem response to solar ultraviolet-B radiation: influence of trophic-level interactions. Science 265:97-100.

Burdon, J. J., and W. J. Müller. 1987. Measuring the cost of resistance to Puccinia coronata Cda in Avena fatua L. Journal of Applied Ecology 24:191-200.

Cain, D. J., S. N. Luoma, J. L. Carter, and S. V. Fend. 1992. Aquatic insects as bioindicators of trace element contamination in cobble-bottom rivers and streams. Canadian Journal of Aquatic Sciences 49:2141-2154.

Cardinale, B. J., and M. A. Palmer. 2002. Disturbance moderates biodiversity-ecosystem function relationships: experimental evidence from Caddisflies in stream mesocosms. Ecology 83:1915-1927.

Clarke, K. R., and R. M. Warwick. 2001. Change in marine communities: an approach to statistical analysis and interpretation, Second edition. PRIMER-E: Plymouth Marine Laboratory, Plymouth, United Kingdom.

Clements, W. H. 1999. Metal tolerance and predator-prey interactions in benthic macroinvertebrate stream communities. Ecological Applications 9:1073-1084.

Clements, W. H. 2004. Small-scale experiments support causal relationships between metal contamination and macroinvertebrate community responses. Ecological Applications 14: 954-967.

Clements, W. H., D. M. Carlisle, J. M. Lazorchak, and P. C. Johnson. 2000. Heavy metals structure benthic communities in Colorado mountain streams. Ecological Applications 10: 626-638.

Clements, W. H., and P. M. Kiffney. 1994. Integrated laboratory and field approach for assessing impacts of heavy metals at the Arkansas River, Colorado. Environmental Toxicology and Chemistry 13:397-404.

Congdon, J. D., A. E. Dunham, W. A. Hopkins, C. L. Rowe, and T. G. Hinton. 2001. Resource allocation-based life histories: a conceptual basis for studies of ecological toxicology. Environmental Toxicology and Chemistry 8: $1698-1703$.

Courtney, L. A., and W. H. Clements. 2000. Sensitivity to acidic $\mathrm{pH}$ in benthic invertebrate assemblages with different histories of metal exposure. Journal of the North American Benthological Society 19:112-127.

Damkaer, D. M., D. B. Dey, and G. A. Heron. 1981. Dosedose-rate responses of shrimp larvae to UV-B radiation. Oecologia 48:178-182.

Davis, A., G. H. W. Deane, and B. L. Diffey. 1976. Possible dosimeter for ultraviolet-radiation. Nature 261:169-170. 
Day, T. A., and P. J. Neale. 2002. Effects of UV-B radiation on terrestrial and aquatic primary producers. Annual Review of Ecology and Systematics 33:371-396.

Groenendijk, D., S. M. G. Lucker, M. Plans, M. H. S. Kraak, and W. Admiraal. 2002. Dynamics of metal adaptation in riverine chironomids. Environmental Pollution 117:101-109.

Gustavson, K., and S. Wangberg. 1995. Tolerance induction and succession in microalgae communities exposed to copper and atrazine. Aquatic Toxicology 32:283-302.

Hare, L. 1992. Aquatic insects and trace-metals: bioavailability, bioaccumulation and toxicity. Critical Reviews in Toxicology 22:327-369.

Harrahy, E. A. 2000. Ecotoxicological and genetic effects of a mixture of heavy metals on selected aquatic macroinvertebrates. Dissertation. Colorado State University, Fort Collins, Colorado, USA.

Heagler, M. G., M. C. Newman, M. Mulvey, and P. M. Dixon. 1993. Allozyme genotype in mosquitofish, Gambusia holbrooki, during mercury exposure: temporal stability, concentration effects and field verification. Environmental Toxicology and Chemistry 12:385-395.

Hill, W. R., S. M. Dimick, A. E. McNamara, and C. A. Branson. 1997. No effects of ambient UV radiation detected in periphyton and grazers. Limnology and Oceanography 42: 769-774.

Kashian, D. R., B. A. Prusha, and W. H. Clements. 2004. The influence of total organic carbon and UV-B radiation on $\mathrm{Zn}$ toxicity and bioaccumulation in aquatic communities. Environmental Science and Technology 38:6371-6376.

Kelly, D. J., M. L. Bothwell, and D. W. Schindler. 2003. Effects of solar ultraviolet radiation on stream benthic communities: an intersite comparison. Ecology 84:2724-2740.

Kiffney, P. M., W. H. Clements, and T. A. Cady. 1997a. Influence of ultraviolet radiation on the colonization dynamics of a Rocky mountain stream benthic community. Journal of the North American Benthological Society. 16: $520-530$.

Kiffney, P. M., E. E. Little, and W. H. Clements. $1997 b$. Influence of ultraviolet-B radiation on the drift response of stream invertebrates. Freshwater Biology 37:485-492.

Landis, W. G., R. A. Matthews, and G. B. Matthews. 1996. The layered and historical nature of ecological systems and the risk assessment of pesticides. Environmental Toxicology and Chemistry 15:432-440.

Macfadyen, E. J., C. E. Williamson, G. Grad, M. Lowery, W. H. Jeffrey, and D. L. Mitchell. 2004. Molecular response to climate change: temperature dependence of UV-induced DNA damage and repair in the freshwater crustacean Daphnia pulicaria. Global Change Biology 10:408-416.

Millward, R. N., and P. L. Klerks. 2002. Contaminant adaptation and community tolerance in ecological risk assessment: introduction. Human and Ecological Risk Assessment 8:921-932.

Niyogi, D. K., L. M. William, Jr., and D. M. McKnight. 2002. Effects of stress from mine drainage on diversity, biomass, and function of primary producers in mountain streams. Ecosystems 5:554-567.

Paine, R. T., M. J. Tegner, and E. A. Johnson. 1998. Compounded perturbations yield ecological surprises. Ecosystems 1:535-545.

Peterson, G., C. R. Allen, and C. S. Holling. 1998. Ecological resilience, biodiversity, and scale. Ecosystems 1:6-18.

Przeslawski, R., A. R. Davis, and K. Benkendorff. 2005. Synergistic effects associated with climate change and the development of rocky shore mollusks. Global Change Biology 11:515-522.

Scheffer, M., S. Carpenter, F. A. Foley, C. Folke, and B. Walker. 2001. Catastrophic shifts in ecosystems. Nature 413: 591-596.

Smith, R. C., et al. 1992. Ozone depletion: ultraviolet radiation and phytoplankton biology in Antarctic waters. Science 255: 952-959.

Van Straalen, N. M., and M. J. T. N. Timmermans. 2002. Genetic variation in toxicant-stressed populations: an evaluation of the "genetic erosion" hypothesis. Human and Ecological Risk Assessment 8:983-1002.

Vinebrooke, R. D., and P. R. Leavitt. 1999. Differential responses of littoral communities to ultraviolet radiation in an alpine lake. Ecology 80:223-237.

Watkins, E. M., D. W. Schindler, M. A. Turner, and D. Findlay. 2001. Effects of solar ultraviolet radiation on epilithic metabolism and nutrient and community composition in a clear-water boreal lake. Canadian Journal of Fisheries and Aquatic Sciences 58:2059-2070.

Weis, J. S. 2002. Tolerance to environmental contaminants in the mumichog, Fundulus heteroclitus. Human and Ecological Risk Assessment. 8:933-953.

West, L. J. A., K. Li, B. M. Greenberg, G. Mierle, and R. E. H. Smith. 2003. Combined effects of copper and ultraviolet radiation on a microscopic green alga in natural soft lake waters of varying dissolved organic carbon content. Aquatic Toxicology 64:39-52.

Williamson, C. E. 1995. What role does UV-B radiation play in freshwater ecosystems? Limnology and Oceanography 40: 386-392.

Wilson, J. B. 1988. The cost of heavy-metal tolerance: an example. Evolution 42:408-413.

Xenopoulos, M. A., P. C. Frost, and J. J. Elser. 2002. Joint effects of UV radiation and phosphorus supply on algal growth rate and elemental composition. Ecology 83:423-435. 